\title{
Mathematical Model for Growth and Removal of Inclusion in a Multi-tuyere Ladle during Gas-stirring
}

\author{
Li Tao WANG, Qiao Ying ZHANG, ${ }^{1)}$ Shi Heng PENG ${ }^{21}$ and Zheng Bang LI \\ Department of Metallurgy Technology, Central Iron and Steel Research Institute, 76 Xue Yuan Nanlu Haidian District, Beijing \\ 100081, China. 1) Metallurgical and Ecological Engineering School, University of Science and Technology Beijing, \\ Beijing 100083, China. $\quad$ 2) Continuous Casting Center, Central Iron and Steel Research Institute, Beijing 100081, China.
}

(Received on October 4, 2004; accepted in final form on December 28, 2004)

\begin{abstract}
A three-dimensional mathematical model has been developed to predict the growth and removal of inclusions during gas stirring in a multi-tuyere ladle. In the model, the efficiency of inclusions removal have been investigated under three different collision mechanisms of Brownian collision, turbulent collision and Stokes collision. Importance of the three approaches of wall adhesion, Stokes flotation and bubbles adhesion to remove inclusions has been analyzed. The results indicated that inclusions growth resulting from turbulent collision is most important and that effect of Stokes collision is remarkable as size of inclusions and difference in size of two particles increase, while inclusion growth resulting from Brown collision is negligible. Removal by Stokes flotation is main manner for large inclusions, while inclusion removal by wall adhesion is negligible. The smaller bubbles contribute the higher efficiency of inclusion removal.
\end{abstract}

KEY WORDS: mathematical model; inclusion growth; inclusion removal; multi-tuyere ladle; gas stirring; bubble flotation.

\section{Introduction}

Gas stirring is the mostly widely used to remove inclusions in refining due to it leads to not only make composition and temperature uniform but also has a function of inclusion removal. With the increasing demand worldwide for high quality metal products, it is essential to further reduce the content of inclusion in molten steel. In this case, importance of gas stirring in steel refining is self-evident.

The method of Mathematical simulation is generally adopted by investigators. Transfer behavior, growth and removal of inclusions in the gas stirring ladle are complicated process, while mathematical simulation makes it possible to efficiently describe and predict the process. Many works have been done in respect of mechanism of inclusion growth and removal. ${ }^{1-10)}$ The literatures on inclusion growth and removal during gas stirring in a ladle were shown in Table 1.

Besides the authors shown in Table 1, many works in respect of inclusion growth and removal have been done by Lifeng Zhang, ${ }^{16,17)}$ Asish Kumar $^{10)}$ and J. Ilegbusi, ${ }^{18)}$ (tundish, VOD), Y. Miki ${ }^{19)}$ (RH), T. A. Engh ${ }^{20)}$ (ASEASKF).

The behaviors of molten steel, bubbles and inclusions have directly effects on the growth and removal of inclusion, furthermore, the behaviors of molten steel, bubbles and inclusions were mainly influenced by the position of tuyere in a ladle. As shown in Table 1, despite great significant efforts made by metallurgist, the tuyere was positioned at the center of bottom of the ladle in all of existing mathematical models. But in steelmaking practice, two tuyeres have been adopted in large capacity ladles. Transfer behav-

Table 1. Summary of mathematical models of inclusion growth and removal in a ladle.

\begin{tabular}{|c|c|c|c|c|c|c|c|c|c|c|}
\hline \multirow{2}{*}{ Authors } & \multirow{2}{*}{ Dimen } & \multirow{2}{*}{$\begin{array}{l}\text { Position } \\
\text { of tuyere }\end{array}$} & \multicolumn{4}{|c|}{ Mechanism of collision } & \multicolumn{3}{|c|}{ Mechanism of removal } & \multirow{2}{*}{ year } \\
\hline & & & Bro & Tur & Sto & Lam & slag & wall & bub & \\
\hline U.Lindborg $^{2)}$ & 2 & Center & & & $\sqrt{ }$ & $\sqrt{ }$ & $\sqrt{ }$ & & & 1968 \\
\hline Sten Linder ${ }^{4)}$ & 2 & Center & & $\sqrt{ }$ & & & $\sqrt{ }$ & & & 1974 \\
\hline $\begin{array}{c}\text { Liangang } \\
\text { Zhao } 11)\end{array}$ & 3 & Center & & $\sqrt{ }$ & & & $\sqrt{ }$ & $\sqrt{ }$ & & 1996 \\
\hline Mats Söder ${ }^{12)}$ & 3 & Center & $\sqrt{ }$ & $\sqrt{ }$ & $\sqrt{ }$ & $\sqrt{ }$ & $\sqrt{ }$ & $\sqrt{ }$ & $\sqrt{ }$ & 2001 \\
\hline $\begin{array}{l}\text { Dong-yuan } \\
\text { sheng }\end{array}$ & 2 & Center & $\sqrt{ }$ & $\sqrt{ }$ & $\sqrt{ }$ & & $\sqrt{ }$ & $\sqrt{ }$ & $\sqrt{ }$ & 2002 \\
\hline Jian Zhang $^{14)}$ & 2 & Center & $\sqrt{ }$ & $\sqrt{ }$ & $\sqrt{ }$ & $\sqrt{ }$ & $\sqrt{ }$ & $\sqrt{ }$ & & 2003 \\
\hline Mats Söder ${ }^{15)}$ & 3 & Center & & $\sqrt{ }$ & $\sqrt{ }$ & $\sqrt{ }$ & $\sqrt{ }$ & $\sqrt{ }$ & $\sqrt{ }$ & 2004 \\
\hline
\end{tabular}

Dimen, dimension; Bro, Brown; Tur, turbulent; Sto, Stokes; Lam, Laminar; Bub, bubble. 
iors of molten steel and inclusion are different in gas stirring ladle with one tuyere and two tuyeres. The object of this paper is to develop a current three-dimensional mathematical model to predict inclusion growth and removal in gas stirring ladle with multi-tuyere and investigate the factor of this process. Flow of molten steel and transfer behavior of inclusion have been studied in this model by use of CFD software package, CFX. Calculation of inclusion growth and removal were carried out by amending transport equation using FORTRAN code. As an application of this model, the distribution of alumina particle in a ladle with different position of tuyere has been calculated.

\section{Mathematical Model}

\subsection{Assumptions}

The mathematical model of inclusion growth and removal in this investigation is based on the following assumptions:

Assumptions concerning the molten steel:

1 the liquid steel inside the ladle is incompressible Newtonian fluid and flow fluid is transient.

2 the effect of slag at top surface of molten steel on flow was not considered.

3 injected gas overflows the top surface of molten steel which was set as free surface, and gravitation and fluctuation of free surface are negligible.

4 the molten steel in a ladle is steady at initial time.

5 the effect of nature convection on flow of molten steel is negligible.

6 the flow of molten steel in a ladle is turbulence flow.

7 the heat flux values of $12500 \mathrm{~W} / \mathrm{m}^{221}$ and $36000 \mathrm{~W} / \mathrm{m}^{222)}$ were respectively used for refractory bricks used in a ladle and free surface of molten steel.

Assumptions concerning bubbles:

8 the bubbles generated at tuyere have the same sizes, and the frequency of bubbles can be calculated by conversation of volume.

9 the generated bubbles are spherical and rigid.

10 interactions of bubbles are negligible.

Assumptions concerning inclusions:

11 inclusions are spherical and uniformly distributed in molten steel at initial time.

12 the size of inclusion particles is so small that the effect of inclusion on flow of molten steel is negligible.

\subsection{Governing Equations}

Based on above assumptions, the following governing equations were solved in the mathematical model:

- the continuity equation,

- the momentum equations,

- the turbulence equation,

- the energy equation.

The parameters which were recommended by Launder and Spalding ${ }^{23)}$ were used in the mathematical model. Their values are: $C_{1}=1.44, C_{2}=1.92, \mu=0.09, \sigma_{k}=1.0, \sigma_{\varepsilon}=1.3$.

The inclusion transport equation is written in the following manner:

$$
\frac{\partial\left(a \rho n_{j}\right)}{\partial t}+\operatorname{div}\left(a \rho u n_{j}\right)-\operatorname{div}\left(a \mu_{\text {eff }} \operatorname{grad} n_{j}\right)=S
$$

In Eq. (1), velocity vector in vertical direct further comprise an increment, i.e. flotation velocity of inclusion, which can calculated by Stokes equation. Source term of inclusion includes contribution of different growth and removal mechanism to its distribution, which will be expounded in the following part.

\subsection{Inclusion Growth and Removal Model}

Oxygen dissolved in molten steel reacts with the added oxidant during refining and oxide particles generated. The size of oxide is small at initial time. With the growth of inclusion, growth mechanism was replaced by different mechanisms. Mechanisms governing inclusion growth are different during the different grown periods due to discrepancy in inclusion diameter and flow behavior of molten steel. In this paper, three mechanism of inclusion growth were considered: Brownian collision, turbulent collision and Stokes collision.

Three mechanisms of inclusion removal were considered: inclusion floating to free surface, adhesion to the ladle wall and adhesion to bubble, and then floating to free surface. The three mechanisms have been compared with each other and investigate the factors of influencing each mechanism in this paper.

\subsubsection{Inclusion Balance Equation}

The inclusion size distribution is governed by conservation of mass within each size range and time step. The following equation suggested by Smoluchowski ${ }^{24}$ is used to predict inclusion distribution:

$$
\frac{d n_{k}}{d t}=0.5 \sum_{i=1}^{i=k-1} f_{i k-i} n_{i} n_{k-i}-\sum_{i=1}^{i_{\max }} f_{i k} n_{i} n_{k}
$$

under the condition,

$$
r_{k-i}^{3}=r_{k}^{3}-r_{i}^{3}
$$

the first term at the right-hand side of Eq. (2) represents mass generation of inclusion in $k$ rank from the agglomeration of smaller particles, $i$ and $j$ rank; the second term represents disappearance from agglomeration into larger particles due to collision with every possible size range and inclusion of each inclusion particle size range.

\subsubsection{Brownian Collision}

Taniguchi $^{25)}$ and Friedlander ${ }^{26)}$ have suggested the following equation to estimate Brownian collision frequency between two particles:

$$
f_{i j}^{\mathrm{B}}=\frac{2}{3} \frac{k_{\mathrm{B}} T}{\mu_{1}}\left(r_{i}+r_{j}\right)\left(\frac{1}{r_{i}}+\frac{1}{r_{j}}\right)
$$

where $T$ is temperature in cell, which can be calculated by solving energy equation.

\subsubsection{Turbulence Collision}

Small particles in the turbulent flow fluid will collide with each other due to action of vortex. The amended collision frequency equation suggested by Saffman and 
Turner ${ }^{27)}$ is written in the following manner:

$$
f_{i j}^{\mathrm{T}}=1.30 \pi^{0.5} a_{\mathrm{t}}\left(\varepsilon / v_{1}\right)^{0.5}\left(r_{i}+r_{j}\right)^{3}
$$

where value of $a_{\mathrm{t}}$ can be calculated by the following equation:

$$
a_{\mathrm{t}}=0.738\left(\mu_{1}\left(r_{i}+r_{j}\right)^{3}\left(\varepsilon / v_{1}\right)^{0.5} / A\right)^{-0.242}
$$

In Eq. (5), $A$ is Hamaker constant, value of which is $2.3 \times$ $10^{-2030)}$ for alumina.

\subsubsection{Stokes Collision}

Inclusion in molten steel can float to free surface due to larger density of steel than that of inclusion. Inclusions in different sizes have different flotation velocities because flotation velocity is in direct proportion to square of inclusion radius. In this way, the difference of flotation velocity between large and small inclusions promotes collision and then the larger collisions generate. Stokes collision rate is calculated by solving equation educed by Tordborg ${ }^{31)}$ :

$$
f_{i j}^{\mathrm{S}}=\frac{2 \pi g\left(\rho-\rho_{\mathrm{p}}\right)}{9 \mu_{1}}\left|r_{i}-r_{j}\right|\left(r_{i}+r_{j}\right)^{3}
$$

\subsubsection{Stokes Flotation}

Inclusion in molten steel float to free surface, and then captured by top slag. Flotation velocity of inclusion is calculated by Stokes equation. Variation of inclusion concentration resulted from free flotation can be predicted by Eq. (7).

$$
\frac{d n_{k}}{d t}=-u_{\mathrm{p}} n_{k} A_{\mathrm{s}} / V_{1}
$$

\subsubsection{Wall Adhesion}

The transport of inclusions to the refractory surface is referred to as a diffusion process. It is assumed that the inclusion move with the molten steel. Zhang ${ }^{16)}$ put forward an empirical equation for the fluid flow near the wall to estimate its variation of concentration:

$$
\frac{d n_{k}}{d t}=-\frac{0.62 \varepsilon^{0.75} \times 10^{-1}}{v_{1}^{1.25}} \frac{S_{\text {wall }}}{V_{1}} r_{k}^{2} n_{k}
$$

\subsubsection{Removal by Bubble Adhesion}

Inclusions can theoretically be removed by bubbles flotation from molten steel in a similar manner as that used in the mineral industry. This is because molten steel does not generally wet the oxides. ${ }^{32)}$ Inclusion can therefore attach to bubbles and be lifted up to the top slog. The contact angle between steel and alumina inclusion which are used as an example is about $140^{\circ} .{ }^{32}$

In this model, the probability of a collision between inclusion and a bubble is calculated by equation educed by Wang et al. ${ }^{33)}$ The overall probability for an inclusion to attach and be lifted to the surface is described as the product of three probabilities ${ }^{34)}$ :

$$
P=P_{\mathrm{a}} \cdot P_{\mathrm{c}} \cdot\left(1-P_{\mathrm{d}}\right)
$$

where $P_{\mathrm{a}}, P_{\mathrm{c}}$, and $P_{\mathrm{d}}$ represent the probability of collision, adhesion and detachment, respectively. The probability of detachment for the very small inclusion is insignificant and can be set to zero for such reason. ${ }^{34)}$ The inclusion is accordingly believed to stick to the bubble once being attached, i.e. $P_{\mathrm{d}}=0$.

Wang modified an equation suggested by Yoon and Lutrell $^{35}$ for calculating the collision probability between an inclusion and a bubble:

$$
P_{\mathrm{c}}=\frac{1}{1-k_{1}}\left[1.5+k_{2}+\frac{2 \operatorname{Re}^{0.72}\left(2+k_{2}\right)}{15\left(1+k_{2}\right)}\right] \frac{k_{2}^{2}}{\left(1+k_{2}\right)^{3}} \ldots
$$

where $k_{1}=u_{\mathrm{p}} / u_{\mathrm{b}}, k_{2}=D_{\mathrm{p}} / D_{\mathrm{b}}, u_{\mathrm{p}}$ and $u_{\mathrm{b}}$ are the inclusion velocity and bubble velocity, respectively; $D_{\mathrm{p}}, D_{\mathrm{b}}$ are the inclusion diameter and bubble diameter, respectively.

When an inclusion has collided with a bubble, it starts sliding over the bubble surface. For the inclusion to get attached, it is required that this sliding time be longer than the time it takes for the thin film between the inclusion and the bubble to rupture. This process can be described as the probability of attachment, $P_{\mathrm{a}}$, which can be expressed $\mathrm{as}^{35)}$ :

$$
P_{\mathrm{a}}=\sin ^{2}\left[2 \arctan \exp \left(-\frac{2 t_{\mathrm{F}}}{D_{\mathrm{b}}+D_{\mathrm{p}}} X\right)\right]
$$

where,

$X$

$$
=\left[1-\frac{3}{4 x_{\mathrm{E}}}-\frac{1}{4 x_{\mathrm{E}}^{3}}+\frac{\mathrm{Re}^{0.72}}{15}\left(-\frac{2}{x_{\mathrm{E}}^{4}}+\frac{1}{x_{\mathrm{E}}^{3}}+\frac{1}{x_{\mathrm{E}}}\right)\right] u_{\mathrm{b}}-u_{\mathrm{p}}
$$

where $x_{\mathrm{E}}=1+k_{2}$.

The film drainage time can be calculated by:

$$
t_{\mathrm{F}}=\frac{3}{64}\left(\frac{\pi}{180}\right)^{2} \frac{b_{\mathrm{a}}\left(32 v_{\mathrm{r}} t_{\mathrm{c}}\right)^{2 m_{\mathrm{a}}} \mu_{1}(2 r)^{3}}{\sigma_{1} k h_{\mathrm{c}}^{2}}
$$

where $b_{\mathrm{a}}, m_{\mathrm{a}}$ and $k$ are constant: $b_{\mathrm{a}}=700, m_{\mathrm{a}}=0.6, k=4^{36)}$; the critical thickness $h_{\mathrm{c}}$, for the film rupture is calculated according to:

$$
h_{\mathrm{cr}}=2.33 \times 10^{-8}\left[10^{3} \sigma_{1}(1-\cos \theta)\right]^{0.16}
$$

An equation for the removal rate of inclusions can then be formulated as:

$$
\frac{d n_{k}}{d t}=-P N_{\mathrm{b}} v_{\mathrm{r}} \pi\left(r_{\mathrm{b}}^{2}+r_{k}^{2}\right) n_{k}
$$

\section{Method of Solution}

In practice, existing of large number of inclusions in various sizes in a ladle results in onerous tasks. In the paper, the method of particle size group ${ }^{37)}$ was adopted. Inclusion radiuses from 10 to $25.2 \mu \mathrm{m}$ were divided into 5 sizes, which are 10, 12.6, 15.9, 20 and $25.2 \mu \mathrm{m}$.

The solutions to the governing equations, boundary conditions and source terms are obtained using the commercial software CFX. The structured finite difference grid is adopted. A typical calculation for $5 \mathrm{~min}$ process of gas stirring requires $15 \mathrm{~h}$ of $\mathrm{CPU}$ time. 


\section{Results and Discussions}

The mathematical model was applied to predict inclusion distribution and turbulence characteristic in a $135 \mathrm{t}$ ladle with two tuyeres. Structure of the ladle is shown in Fig. 1. Figure 2 shows structure of tuyere used in the ladle and its position in bottom. The following parameters of fluid and gas used in the model were shown in Table 2. Assuming that inclusion have same radius of $10 \mu \mathrm{m}$ and its number concentration is $\left.4.2 \times 10^{12} 11\right)$ at initial time.

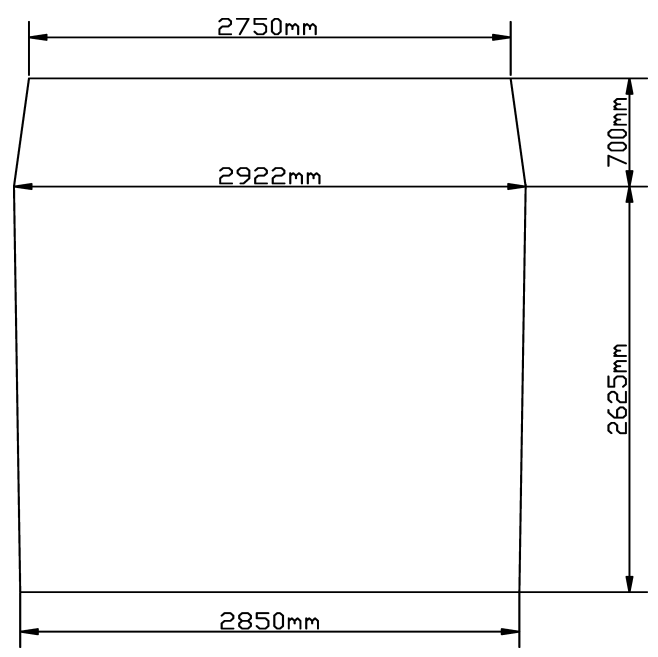

Fig. 1. Structure of a two-tuyere ladle.

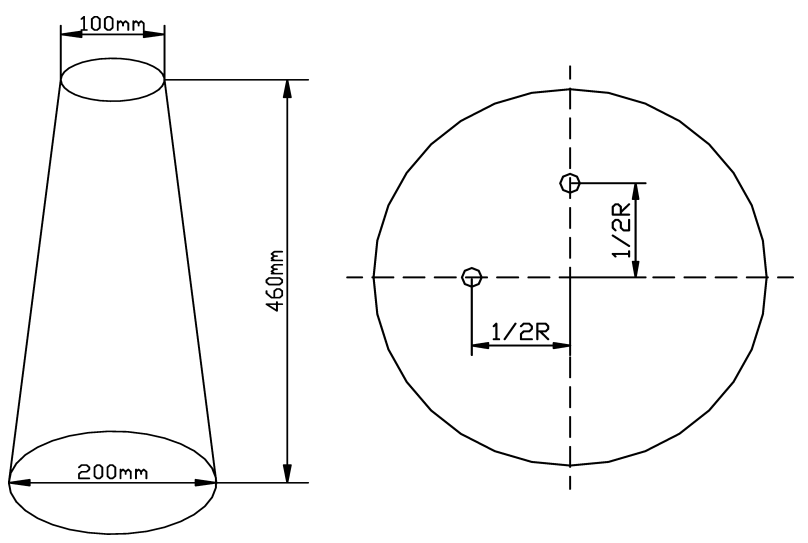

Fig. 2. structure of the two tuyeres used in $135 \mathrm{t}$ ladle and its position in ladle bottom.

\subsection{Flow Behavior of Molten Steel}

Flow behavior of molten steel in a $135 \mathrm{t}$ ladle with two tuyeres has been predicted at $5 \mathrm{~min}$ after gas injection. Figures 3(a) and 3(b) is flow field and turbulence kinetic energy at 5 min after gas injection. Length and direction of the arrows shown in Fig. 3 represent value of velocity and flow direction, respectively. Molten steel above and between the two tuyeres flow upward due to gas stirring and flow to wall of ladle at free surface, and then flow downward again. As a result, a small circular flow appears at position between tuyere and wall, and its center located at top part of ladle. The flow patterns of two sides are symmetrical. It is obvious that velocity of molten steel above the two tuyeres and at free surface is higher than that at other position.

From Fig. 3(b), it can be seen that distribution of turbulence kinetic energy is corresponding to velocity distribution shown in Fig. 3(a). The larger turbulence kinetic energy gradient exists in whole ladle and the largest turbulence kinetic energy located at region above the two tuyeres. Value of the turbulence kinetic energy is up to $0.016 \mathrm{~m}^{2} / \mathrm{s}^{2}$ when flow rate of argon is $1.39 \mathrm{~m}^{3} / \mathrm{s}$.

Table 2. Parameters used in model.

\begin{tabular}{|c|c|c|}
\hline Parameters & Value & Unit \\
\hline Volume fraction of gas $a$ & 0.05 & $\%$ \\
\hline Flow rate of gas $Q$ & 1.39 & $\mathrm{~m}^{3} / \mathrm{s}$ \\
\hline Density of steel $\rho$ & $7.02 \times 10^{3}$ & $\mathrm{Kg} / \mathrm{m}^{3}$ \\
\hline Viscosity of molten steel $\mu_{1}$ & $5.5 \times 10^{-3}$ & $\mathrm{Kg} /(\mathrm{m} \cdot \mathrm{s})$ \\
\hline Specific heat of molten steel $C_{\mathrm{pl}}$ & 755 & $\mathrm{~J} /(\mathrm{kg} \cdot \mathrm{K})$ \\
\hline Thermal conductivity of molten steel $k_{\mathrm{Tl}}$ & 41 & $\mathrm{~W} /(\mathrm{m} \cdot \mathrm{k})$ \\
\hline Surface tension $\sigma_{\mathrm{l}}$ & 1.6 & $\mathrm{~N} / \mathrm{m}$ \\
\hline Density of gas $\rho_{\mathrm{g}}$ & $0.322^{13)}$ & $\mathrm{Kg} / \mathrm{m}^{3}$ \\
\hline Viscosity of gas $\mu_{\mathrm{g}}$ & $2.25 \times 10^{-5}$ & $\mathrm{Kg} /(\mathrm{m} \cdot \mathrm{s})$ \\
\hline Specific heat of argon $C_{\mathrm{pg}}$ & 525 & $\mathrm{~J} /(\mathrm{kg} \cdot \mathrm{K})$ \\
\hline Thermal conductivity of argon $k_{\mathrm{Tg}}$ & 0.0164 & $\mathrm{~W} /(\mathrm{m} \cdot \mathrm{k})$ \\
\hline Density of alumina $\rho_{\mathrm{p}}$ & 3960 & $\mathrm{Kg} / \mathrm{m}^{3}$ \\
\hline
\end{tabular}

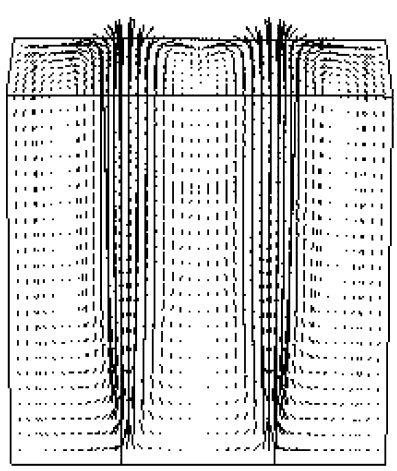

a flow field

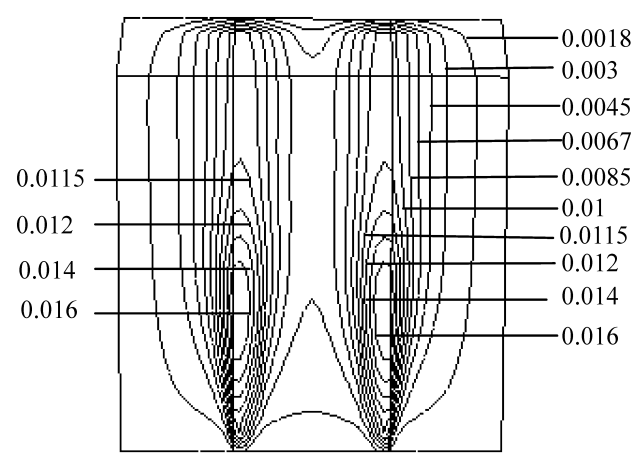

b turbulence kinetic energy (unit: $\mathrm{m}^{2} / \mathrm{s}^{2}$ )

Fig. 3. Distribution of flow patterns and turbulent kinetic energy in a $135 \mathrm{t}$ ladle with two tuyeres at $300 \mathrm{~s}$ after the start of gas stirring. 

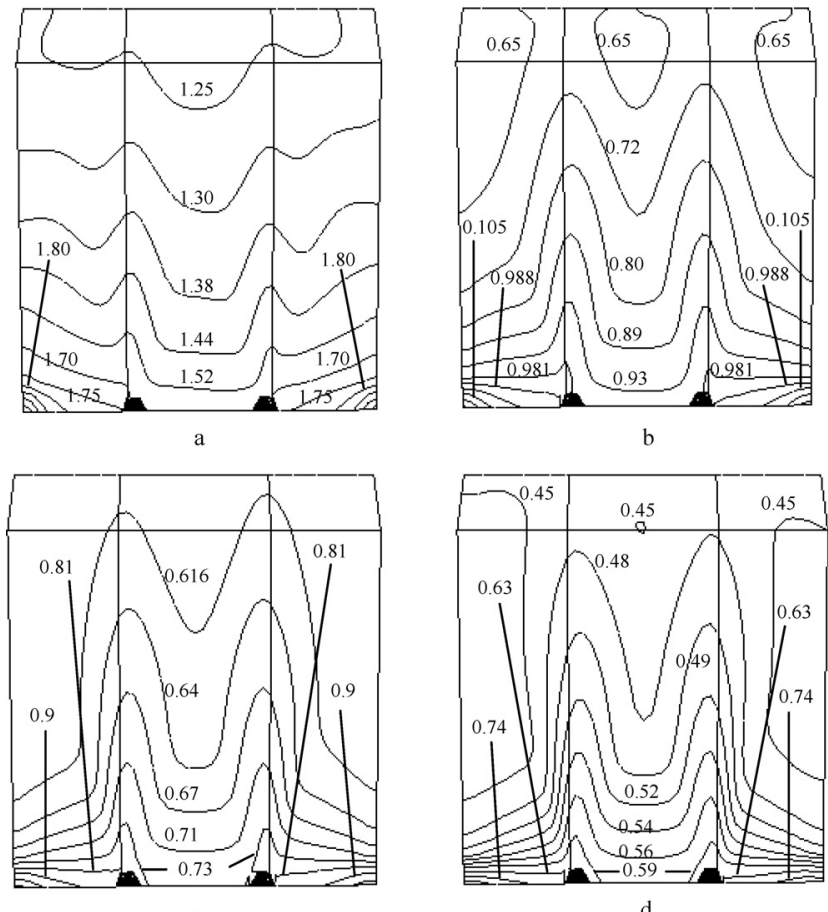
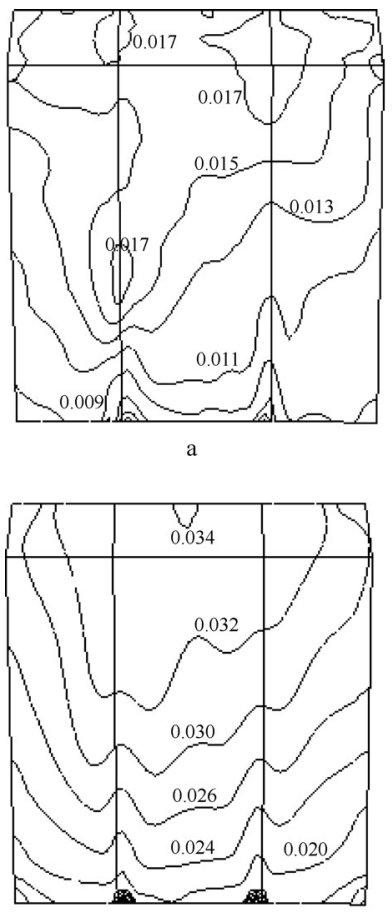

$\mathrm{c}$

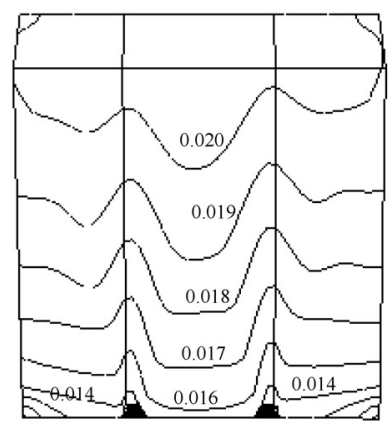

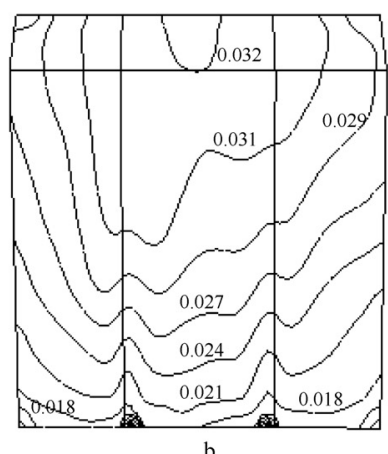

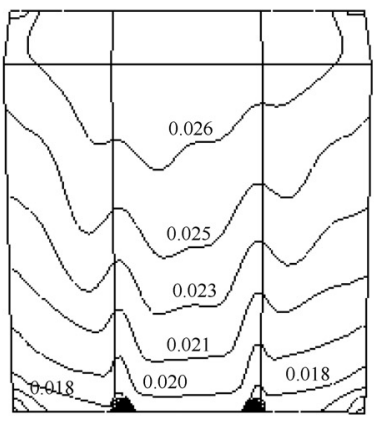

d

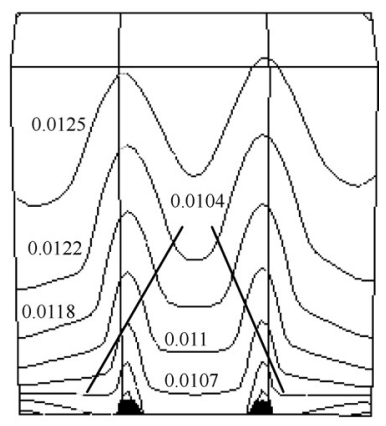

f gradient becomes small, which lead to more uniform distribution of inclusion in molten steel along with gas stirring. But concentration gradient still exists at $5 \mathrm{~min}$ after start of the gas stirring and the lowest concentration is above the two tuyeres. The concentration of inclusion at position of the wall of the ladle contacting with bottom of ladle is highest. Considering the case of velocity distribution (Fig. 3(a)), the reason for this is that molten steel have stronger turbulence kinetic energy in a region above the two tuyeres, which promote interaction of inclusion in this region. But on the contrary, concentration of inclusion in larger size in this region is higher. This case indicated that collision frequency of small inclusions with each other in this region is higher than that in other region, and then greater numbers of large inclusions is generated. Further, as shown in Fig. 5, it can be seen that variation of concentration of large size inclusion went through the process of increasing and then decreasing. This case indicated that a large number of large size inclusions generated in short time result from collision of small inclusions each other at the beginning of gas stirring. Thus, the generated large inclusions were removed by various mechanisms with the process of gas stirring.

\subsection{Effect of Different Growth Mechanisms on Colli- sion Frequency}

To investigate the importance of each collision mecha-

Fig. 5. Concentration distribution of inclusion in radius of $20 \mu \mathrm{m}$ in a $135 \mathrm{t}$ ladle with two tuyeres in $300 \mathrm{~s}$ after the start of gas stirring (unit: $10^{10} \mathrm{n} / \mathrm{m}^{3}$ ).

nism, frequency of Brownian collision, turbulence collision and Stokes collision has been calculated, as shown in Fig. 6. Size of inclusion has great effect on frequency of each collision. In spite of inclusion size, inclusions growth resulting from Brownian collision is negligible; the larger difference in size of two particles is, the more remarkable the effect of Stokes collision on inclusion growth is; moreover, frequency of collision between two particles in large size is higher than that of collision between two particles in the small sizes as rate of the two particles in size is constant. The reason for this case is that flotation velocity of two inclusions in the former is larger than that in the latter because flotation velocity of inclusions is directly proportion to inclusion size. It also can be seen from Fig. 6 that frequency of Stokes collision (curve b) takes minimal value, which is zero, for two particles (the radius of which is $r_{1}$ and $r_{2}$ respectively) in the same sizes. The reason is that Stokes collision happens only for particles in different sizes, while it is impossible for particles in the same sizes. Contribution of turbulence collision to inclusion growth depends on inclusion size and turbulence kinetic energy. 

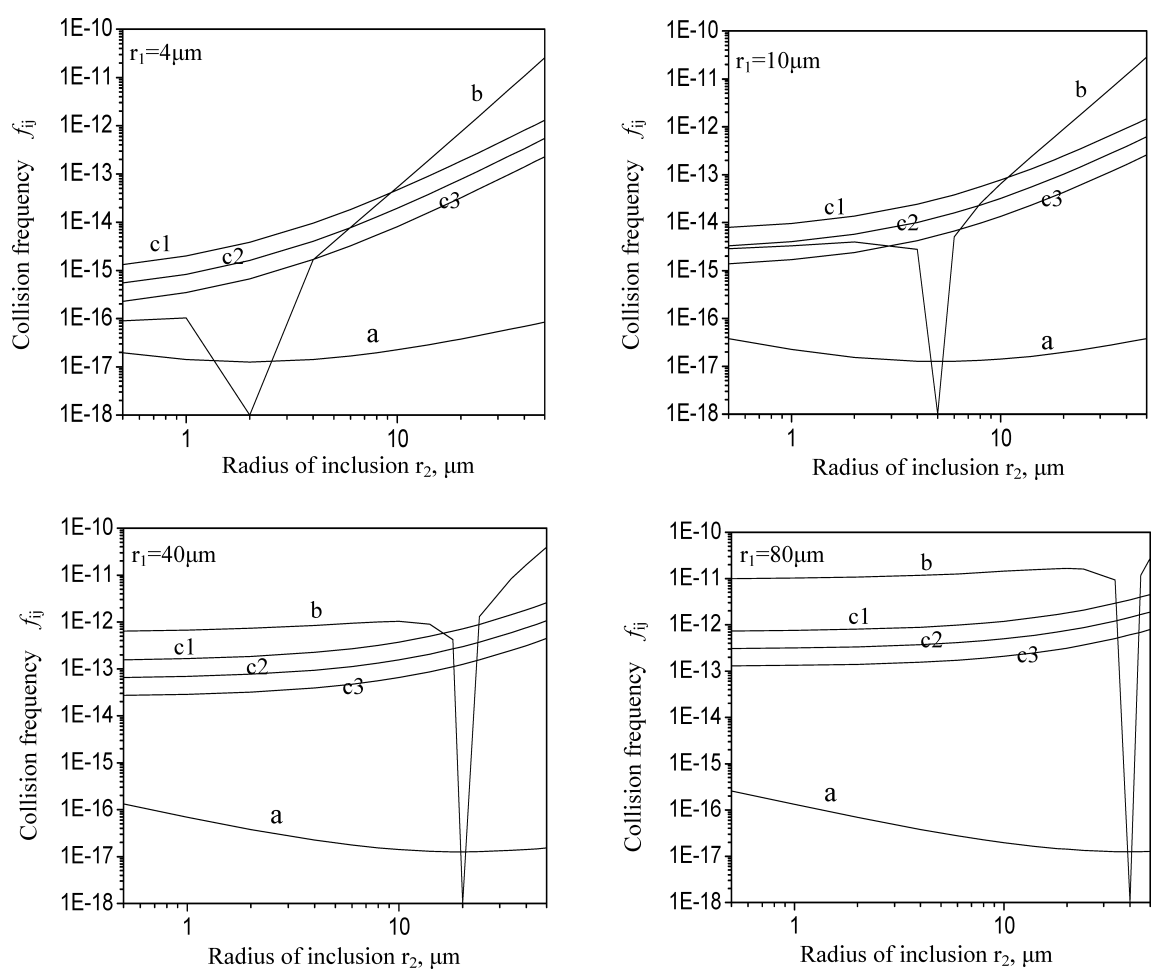

Fig. 6. Effect of different collision mechanisms on collision frequency.

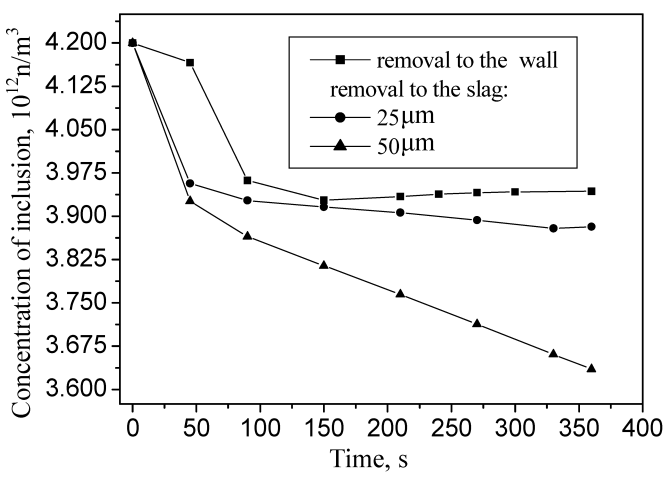

a Wall and slag adhesion

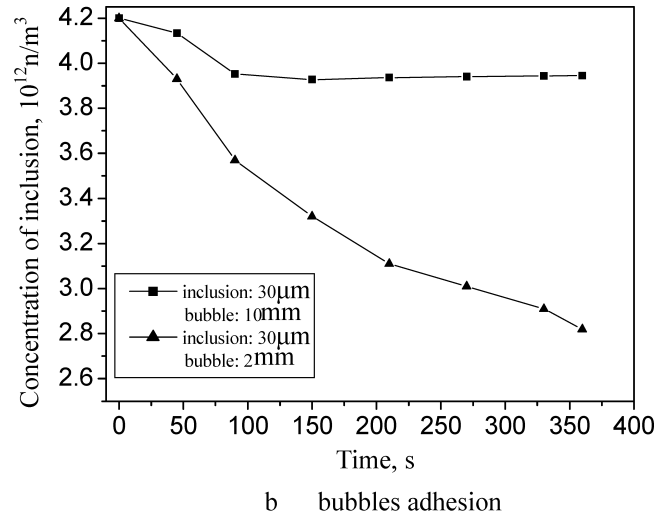

b bubbles adhesion

Fig. 7. Effect of different removal mechanism on inclusion removal efficiency.

Turbulence collision frequency is consistent with the larger inclusions and turbulence kinetic energy.

Figure 7 shows the effect of various removal mechanisms on inclusion concentration distribution. The data shown in Fig. 7 were gained by investigating the removal mechanism without considering of collision and aggregation of inclusions each other respectively. From Fig. 7(a), inclusion removal efficiency due to wall adhesion is lowest. Removal efficiency of inclusion in diameter of $25 \mu \mathrm{m}$ by Stokes flotation is also lower, while that of inclusion in diameter of $50 \mu \mathrm{m}$ relatively remarkable because small inclusions have lower flotation velocity than that of large inclusions. For this reason, it is pointed out that the possibility of small inclusions removal by Stokes flotation is very low. If inclusions adhere to bubbles, they can be removed by floating to the surface along with the bubble, which is consistent with calculating results, as shown in Fig. 7(b). Effect of bubble size on inclusion removal efficiency is distinct. The removal efficiency of small bubbles $(2 \mathrm{~mm})$ on inclusion is higher than that of large bubbles $(10 \mathrm{~mm})$. But generally, the diameter of bubbles generated through tuyeres in gas stirring ladle is at range of 10 to $20 \mathrm{~mm},{ }^{38)}$ so removal efficiency of inclusion by bubble adhesion is very low. In this case, it is essential to develop a new method to generate smaller bubbles to improve inclusion removal efficiency in gas stirring ladle.

\section{Conclusions}

In this study, a mathematical model has been developed to predict inclusion growth and removal efficiency in gas stirring ladle with two tuyeres. The efficiency of inclusions removal has been investigated under three different collision mechanisms of Brownian collision, turbulent collision and Stokes collision. Importance of the three approaches of wall adhesion, Stokes flotation and bubbles adhesion on inclusions removal has been analyzed. The mathematical model was applied to predict alumina inclusion distribution and turbulence characteristic in a $135 \mathrm{t}$ ladle provided with two tuyeres. 
The results indicated that inclusion growth resulting from turbulent collision is most important and effect of Stokes collision is remarkable as increase of inclusion size, while inclusion growth resulting from Brownian collision is negligible. Removal by Stokes flotation is the main manner for large inclusions, while that of small inclusions is very low. Inclusion removal by wall adhesion is negligible. Generally, efficiency of inclusion removal by bubble adhesion is low due to the oversize of bubbles generated through the tuyere in gas stirring ladle, while the smaller bubbles have higher inclusion removal efficiency than large bubbles. So it is essential to develop a new method to generate smaller bubbles to improve inclusion removal efficiency in the molten steel.

\section{Nomenclature}

a: Volume fraction

A: Hamaker constant

$A_{\mathrm{s}}:$ Area of slag

$C_{\mathrm{pl}}, C_{\mathrm{pg}}:$ Specific heat of molten steel and argon

$b_{\mathrm{a}}, m_{\mathrm{a}}, k:$ Constant

$D_{\mathrm{p}}, D_{\mathrm{b}}$ : Diameter of inclusion and bubble, respectively

$f_{i j}$ : Collision frequency function

$h$ : Height of ladle

$k_{\mathrm{Tl}}, k_{\mathrm{Tg}}$ : Thermal conductivity of molten steel and argon

$k_{\mathrm{B}}$ : Boltzmann's constant

$(\mathrm{W} / \mathrm{m} \cdot \mathrm{k})$

$n_{j}$ : Number concentration of inclusion in $i$ rank

$\left(\mathrm{n} / \mathrm{m}^{3}\right)$

$n_{k}$ : Number density of inclusion in $k$ rank at the surface

$\left(\mathrm{n} / \mathrm{m}^{3}\right)$

$N_{\mathrm{b}}$ : Total number of bubbles

$\left(\mathrm{n} / \mathrm{m}^{3}\right)$

$P$ : Total probability

$P_{\mathrm{a}}$ : Probability of collision

$P_{\mathrm{c}}$ : Probability of adhesion

$P_{\mathrm{d}}$ : Probability of detachment

$Q$ : Flow rate of gas

$r, r_{1}, r_{2}$ : Radius of inclusion

$\left(\mathrm{m}^{3} / \mathrm{s}\right)$

$r_{k-i}, r_{k}, r_{i}$ : Radius of inclusion in $k-i, k$ and $i$ rank (m)

$r_{\mathrm{b}}$ : Radius of bubbles

Re: Reynolds number

$S$ : Source of inclusion

$S_{\text {wall }}$ : Area of wall

$t$ : Time

$t_{\mathrm{F}}:$ Film drainage time

$T$ : Temperature of molten steel

$u$ : Liquid velocity

$(\mathrm{m} / \mathrm{s})$

$u_{\mathrm{p}}$ : Flotation velocity of inclusion

$(\mathrm{m} / \mathrm{s})$

$u_{\mathrm{b}}$ : Flotation velocity of bubble

$(\mathrm{m} / \mathrm{s})$

$\left(\mathrm{m}^{2} / \mathrm{s}\right)$

$(\mathrm{m} / \mathrm{s})$

$\left(\mathrm{m}^{3}\right)$

$\left(\mathrm{m}^{2} / \mathrm{s}\right)$

$V_{1}$ : Volume of molten steel

$\varepsilon$ : Turbulence energy dissipation rate

$\mu_{\text {eff }}:$ Effective diffusion coefficient

$(\mathrm{K} / \mathrm{m} \cdot \mathrm{s})$ $\mu_{1}, \mu_{\mathrm{g}}: \quad$ Molecular viscosity of molten steel and argon

$(\mathrm{kg} / \mathrm{m} \cdot \mathrm{s})$

$\sigma_{1}:$ Surface tension of molten steel

$\theta$ : Contact angle

$\rho, \rho_{\mathrm{p}}$ : Density of molten steel and inclusion $\left(\mathrm{kg} / \mathrm{m}^{3}\right)$

\section{REFERENCES}

1) P. G. Saffmen and J. S. Turner: J. Fluid Mech., (1956), 16.

2) U. Lindborg and K. Torssell: Trans. Metall. Soc. AIME, 242 (1968), 94.

3) R. K. Iyengar and W. O. Philbrook: Metall. Trans., 3 (1972), 1823.

4) S. Linder: Scand. J. Metall., (1974), 137.

5) K. Nakanishi and J. Szekely: Trans. Iron Steel Inst. Jpn., 15 (1975), 522 .

6) K. Shirabe and J. Szekely: Trans. Iron Steel Inst. Jpn., 23 (1983), 465.

7) Y. Miki, Y. Shimada and B. G. Thomas: Iron Steelmaker, 24 (1997), 31.

8) T. A. Engh and N. Lindskog: Scand. J. Metall., 4 (1975), 49.

9) H. Tozawa, Y. Kato and K. Sorimachi: ISIJ Int., 39 (1999), 426.

10) A. K. Sinha and Y. Sahai: ISIJ Int., 33 (1993), 556.

11) L. G. Zhao: Ph. D. Thesis, Northeastern University, (1996).

12) M. Söder, P. Jönsson and L. Jonsson: Steelmaking Conf. Proc., ISS/AIME, Warrendale, PA, (2001), 673.

13) D.- Y. Sheng, M. Söder and P. Jönsson: Scand. J. Metall., 31 (2002), 134.

14) J. Zhang and H. G. Lee: CSM Annual Meeting Proc., CSM, Beijing, (2003), 613.

15) M. Söder, P. Jönsson and L. Jonsson: Steel Res. Int., 75 (2004), 128.

16) L. Zhang and K. Cai: Steelmaking Conf. Proc., ISS/AIME, Warrendale, PA, (2001), 275.

17) L. Zhang, S. Taniguchi and K. Cai: Metall. Mater. Trans. B, 31B (2000), 253.

18) O. J. Ilegbusi and J. Szekely: ISIJ Int., 29 (1989), 1031.

19) Y. Miki, Y.Shimada and B. G.Thomas: Iron Steelmaker, 24 (1997), 31.

20) T. A. Engh and N. Lindskog: Scand. J. Metall., 4 (1975), 49.

21) A. H. Castillejos E., M. E. Salcudean and J. K. Brinacombe: Metall. Trans. B, 20B (1989), 603.

22) S. Peng: Ph. D. Thesis, South-Central University, (1999).

23) B. E. Launder and D. B. Spalding: Comput. Methods Appl. Mech. Eng., (1974), 269.

24) M. V. Smoluchowski: Z. Phys. Chem., 92 (1917), 129.

25) S. Taniguchi and A. Kikuchi: Tetsu-to-Hagané, 78 (1992), 527.

26) S. K. Friedlander and C. S. Wang: J. Colloid Interface Sci., 22 (1966), 126.

27) P. G. Saffman and Js. Turmer: J. Fluid Mech., (1956), 16

28) K. Higashitani, K. Yamauchi and Y. Matsuno: J. Chem. Eng. Jpn., 16 (1983), 299.

29) K. Higashitani, K. Yamauchi and Y. Matsuno: J. Chem. Eng. Jpn., 16 (1983), 299.

30) S. Taniguchi, A. Kikuchi and T. Ise: ISIJ Int., 36 (1996), S117.

31) U. Lindborg and K. Torssell: Trans. Metall. Soc. AIME, 242 (1968), 94.

32) A. W. Cramb and I. Jimbo: W. O. Philbrook Mem. Symp. Conf. Proc., ISS, Warrendale, PA, (1988), 258.

33) L. Wang, H. G. Lee and P. Hayes: ISIJ Int., 36 (1996), 7.

34) W. J. Trahar: Int. J. Min. Proc., 8 (1981), 289.

35) R. H. Yoon and G. H. Lutrell: Min. Process. Extractive Metall. Rev., 4 (1989), 101.

36) H. J. Schulze: Miner. Process. Extrac. Metall. Rev., 5 (1989), 43.

37) T. Nakaoka, S. Taniguchi and K. Matsumoto: ISIJ Int., 41 (2001), 1103.

38) Y. Xie and F. Oeters: ISIJ Int., 32 (1992), 66. 